\title{
The anti-aging properties of a human placental hydrolysate combined with dieckol isolated from Ecklonia cava
}

\author{
Su Kil Jang ${ }^{1 \dagger}$, Do Ik Lee ${ }^{2 \dagger}$, Seung Tae Kim', Gwang Hoon Kim', Da Woon Park', Jung Youl Park , Daehee Han', \\ Jae Kwon Choi ${ }^{4}$, Yoon-bok Lee ${ }^{4}$, Nam-Soo Han ${ }^{5}$, Yun Bae Kim', Jeongsu Han ${ }^{6}$ and Seong Soo Joo ${ }^{1 *}$
}

\begin{abstract}
Backgrounds: In the present study, we aimed to examine the anti-aging properties of human placental hydrolysate (HPE) and dieckol (DE) from Ecklonia cava against free radical scavenging, muscle hypertrophy-related follistatin mRNA expression, amelioration of cognition-related genes and proteins, inhibition of collagenase-regulating genes, and elastinase activity.

Methods: The anti-aging effects were examined in human fibroblast (CCD986sk), mouse myoblast (C2C12), and neuroblastoma (N2a) cell models, by employing various assays such as 2,2-diphenyl-1-picrylhydrazyl hydrate (DPPH) scavenging, hydroxyl radical-mediated oxidation, quantitative real-time polymerase chain reaction, enzyme activity, and immunocytochemistry observation.

Results: Our results show that HPE combined with DE (HPE:DE) strongly scavenged DPPH radicals and protected proteins against degradation by hydroxyl radical attack. HPE:DE effectively inhibited matrix metalloproteinase-1 expression, protein kinase $\mathrm{C}$ alpha expression, and elastinase activity. Furthermore, HPE:DE improved the expression of cognition-related genes (choline acetyltransferase and vesicular acetylcholine transporter). These events may proactively contribute to retard the aging processes and the abrupt physiological changes probably induced by mitochondrial dysfunction with aging.

Conclusions: Based on these findings, we conclude that the combined treatment of HPE:DE may be useful for anti-aging therapy in which the accumulation of oxidative damage is the main driving force.
\end{abstract}

Keywords: Human placental hydrolysate, Dieckol, Muscle, Cognition, Collagenase, Mitochondria

\section{Background}

Aging is a series of biological changes that follow a natural progression from birth to death and is a multidimensional process of physical, psychological, and social changes. Identifying the major contributing factors to aging and increasing longevity without age-related illness is a cherished desire for human beings. Although much scientific knowledge has accumulated, preventing aging and prolonging lifespan continue to be a focus of attention. Aging-associated diseases that are not age-specific include atherosclerosis and cardiovascular disease, cancers, arthritis,

\footnotetext{
* Correspondence: ssj66@gwnu.ac.kr

${ }^{\dagger}$ Equal contributors

'Department of Marine Molecular Biotechnology, College of Life Science, Gangneung-Wonju National University, 120 Gangneung Daehangno,

Gangneung, Gangwon 210-702, Republic of Korea

Full list of author information is available at the end of the article
}

cataracts, osteoporosis, type 2 diabetes, hypertension, and Alzheimer's disease [1]. Excess production of free radicals may cause age-related impairment through oxidative damage to biomolecules, and mitochondria are the main target of free radical attack [2-4]. In addition, age-associated cognitive decline and neurogenic impairment, which may be caused by reduced superoxide dismutase and increased oxidative stress during aging, are important during aging but not fully understood $[5,6]$. Human placenta, which includes diverse bioactive molecules, has attracted attention for managing the aging process $[7,8]$. The placenta also possesses anti-oxidative, anti-inflammatory, anti-melanogenic, and collage-synthesizing properties that are effective anti-aging agents and rejuvenating to the body [9-11]. Dieckol (DE) was recently isolated from Ecklonia species, and this oligomeric polyphenol 
Table 1 Primer sequences used for the real-time polymerase chain reaction analysis

\begin{tabular}{|c|c|c|c|c|c|}
\hline Gene & & Primer & Amino acid sequence & Product size (bp) & Accession No. \\
\hline \multirow[t]{6}{*}{ Human } & MMP1 & 5' Primer & 5'- TAGTGGCCCAGTGGTTGAAA & 228 & NM_002421 \\
\hline & & 3' Primer & 5'-CCAGATTTGCCAAGAGCAGA & & \\
\hline & PKCa & 5' Primer & 5'-CCTTCCTTTGGAGTTTCGG & 228 & NM_002737 \\
\hline & & 3' Primer & 5'-CCAACAACCTTGACCGAGTG & & \\
\hline & GAPDH & 5' Primer & 5'- GGAGCCAAAAGGGTCATCAT & 203 & AK_026525 \\
\hline & & 3' Primer & 5'- GTGATGGCATGGACTGTGGT & & \\
\hline \multirow[t]{8}{*}{ Mouse } & MAP-2 & 5' Primer & 5'- ACCACACCTGCAGTGGAGAA & 227 & M21041 \\
\hline & & 3' Primer & 5'- AATCTGGACCTGGTTCCTGC & & \\
\hline & NGF & 5' Primer & 5'- TACTGCACCAATAGCTGCCC & 191 & NM_013609 \\
\hline & & 3' Primer & 5'- TTCAACAGGACTCACCGGA- & & \\
\hline & FSTN & 5' Primer & 5'- GCTCTCTCTGCGATGAGCTG & 174 & NM_008046 \\
\hline & & 3' Primer & 5' ATCTCGGAAGAAACGGAGGA- & & \\
\hline & $\beta$-actin & 5' Primer & 5'-TACAGCTTCACCACCACAGC & 187 & NM_007393 \\
\hline & & 3' Primer & 5'-AAGGAAGGCTGGAAAAGAGC & & \\
\hline
\end{tabular}

of phloroglucinols [12] has been reported to have diverse biological activities, such as antioxidant [13], anti-plasmin inhibitory [14], anti-mutagenic, anti-bacterial [15], antiviral [16], tyrosinase inhibitory [17], anti-adipogenic [18], and matrix metalloproteinase-1 (MMP-1) inhibitory activities [19]. Thus, we hypothesized that increased free radical production may play a central role in aging and cause muscle and neuronal damage. In this study, we report the optimal effects of a human placental hydrolysate (HPE) combined with DE by focusing on the enhancement of aging-related indices, such as oxidative stress and muscle and cognitive impairment.

\section{Methods}

\section{Sample preparation}

Fresh E. cava was collected from the Jeju Island coast of South Korea in February 2013. A voucher specimen (NIBRAL0000145247) was authenticated by Prof. Joo (Biopharmaceutical Lab, College of Life Science, Gangneung National University, Republic of Korea), and deposited at the National Institute of Biological Resources, Incheon, Republic of Korea. Epiphytes, salt, and sand were completely removed with tap water. The samples were sanitized with $70 \%$ ethanol, rinsed with deionized water, and freeze-dried. Finely ground E. cava (100 g) was steeped in $1 \mathrm{~L}$ of $80 \%$ aqueous ethanol for $24 \mathrm{~h}$ repeatedly for 3 days at room temperature. The ethanol hydrolysates were combined, filtered through filter paper (Whatmann International Ltd., Maidstone, UK), evaporated, and dried completely. After the hydrolysate was suspended on $1 \mathrm{~L}$ distilled water, the organic soluble fraction was obtained with ethyl acetate. Finally, DE was obtained by purifying the polar fraction using the Prep-LC (LC-9104, JAI) system equipped with an ODS column in methanol solvent as
Table 2 Amino acid composition

\begin{tabular}{|c|c|c|c|}
\hline Classification & Amino acid & $\mathrm{g} / 100 \mathrm{~g}$ & $\%$ \\
\hline \multirow[t]{2}{*}{ Sulphuric amino acids } & Cysteine & 0.13 & 0.4 \\
\hline & Methionine & 0.59 & 1.7 \\
\hline \multirow[t]{2}{*}{ Aromatic amino acids } & Phenylalanine & 1.32 & 3.8 \\
\hline & Tyrosine & 0.49 & 1.4 \\
\hline \multirow[t]{10}{*}{ Essential amino acids } & Leucine & 3.01 & 8.7 \\
\hline & Lysine & 2.69 & 7.8 \\
\hline & Arginine $^{a}$ & 2.68 & 7.7 \\
\hline & Valine & 2.04 & 5.9 \\
\hline & Threonine & 1.68 & 4.9 \\
\hline & Isoleucine & 1.37 & 4.0 \\
\hline & Phenylalanine & 1.32 & 3.8 \\
\hline & Histidine $^{a}$ & 0.91 & 2.6 \\
\hline & Methionine & 0.59 & 1.7 \\
\hline & (Sub-total) & 16.29 & 47.1 \\
\hline \multirow[t]{9}{*}{ Nonessential amino acids } & Glutamine & 4.13 & 11.9 \\
\hline & Glycine & 3.5 & 10.1 \\
\hline & Asparagine & 3.04 & 8.8 \\
\hline & Proline & 2.74 & 7.9 \\
\hline & Alanine & 2.58 & 7.5 \\
\hline & Serin & 1.71 & 4.9 \\
\hline & Tyrosine & 0.49 & 1.4 \\
\hline & Cysteine & 0.13 & 0.4 \\
\hline & (Sub-total) & 18.32 & 52.9 \\
\hline
\end{tabular}

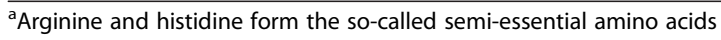




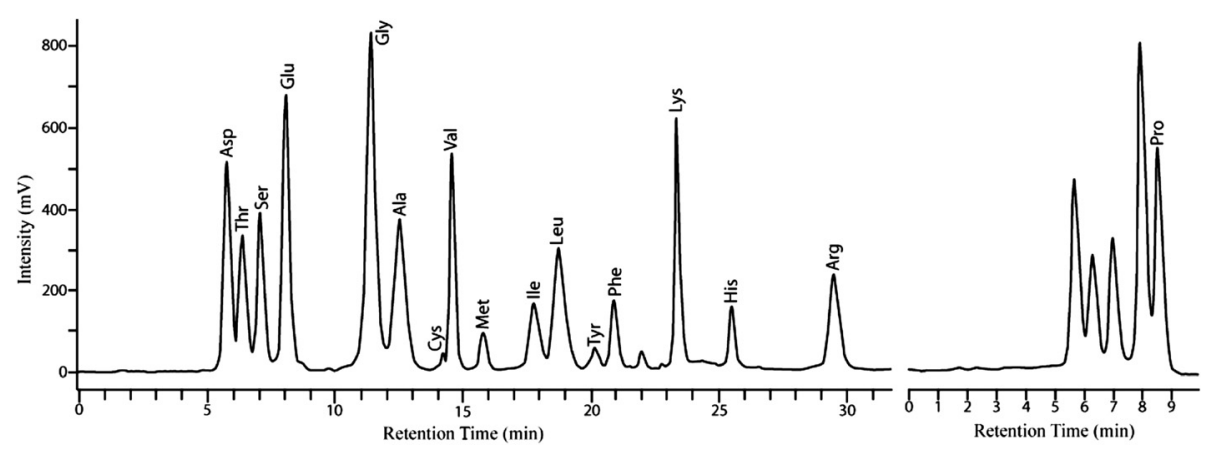

Fig. 1 Typical amino acid chromatogram from the human placental hydrolysate (HPE)

described previously [20]. The HPE (Laennec, human placenta hydrolysate) was obtained from Japan Bioproducts Industry Co., Ltd. (Tokyo, Japan).

\section{Amino acid analysis}

Amino acid concentrations were measured with an automatic amino acid analyzer (L-8800; Hitachi, Tokyo, Japan). Sample aliquots containing 8-12 mg protein were placed in a $20-\mathrm{mL}$ cuvette and mixed with $9 \mathrm{~mL}$ of $6 \mathrm{M} \mathrm{HCl}$. After sealing the cuvette, the samples were hydrolyzed at $110{ }^{\circ} \mathrm{C}$ for $24 \mathrm{~h}$ under $\mathrm{N}_{2}$. The hydrolysates were transferred to a $100 \mathrm{~mL}$ volumetric flask, mixed with $9 \mathrm{~mL} 6 \mathrm{M}$ $\mathrm{NaOH}$, and diluted with $0.02 \mathrm{~N} \mathrm{HCl}$. Then, all samples were filtered and loaded in a Hitachi L-8800 amino acid analyzer for the analysis.

\section{Radical scavenging and protein protection assays}

The 2,2-diphenyl-1-picrylhydrazyl hydrate (DPPH) radical is one of the few stable organic nitrogen radicals and has a deep-purple color. Fractions were reacted with the DPPH solution to evaluate free radical scavenging activity. Each lyophilized fraction was dissolved in dimethyl sulfoxide (DMSO, Sigma-Aldrich) as a stock solution $(100 \mathrm{mg} / \mathrm{mL})$, and each fraction was reacted with $0.3 \mathrm{mM} \mathrm{DPPH}$ in methanol. Various concentrations of HPE or DE $(0.01-100 \mu \mathrm{g} / \mathrm{mL})$ were reacted with the DPPH radical solution for $20 \mathrm{~min}$ at room temperature, and absorbance was measured at $517 \mathrm{~nm}$. DPPH free radical scavenging activity was calculated using the following equation: $\mathrm{DPPH}$ scavenging activity $(\%)=[\mathrm{Ac}-(\mathrm{A}-\mathrm{As})] / \mathrm{Ac} \times 100$, where Ac is the absorbance of the control DPPH solution, A is absorbance of the sample with the DPPH solution, and As is absorbance of the sample. Hydroxyl radicalmediated oxidation experiments were performed for the protein protection assay using a metal-catalyzed reaction, as described previously with some modifications [21]. The target protein, bovine serum albumin (BSA), was dissolved in a $150 \mathrm{mM}$ phosphate buffer ( $\mathrm{pH}$ 7.3) to a final concentration of $0.5 \mathrm{mg} / \mathrm{mL}$. The BSA solution was incubated with and without $100 \mu \mathrm{M}$ copper $\left(\mathrm{Cu}^{2+}\right)$ and $2.5 \mathrm{mM}$

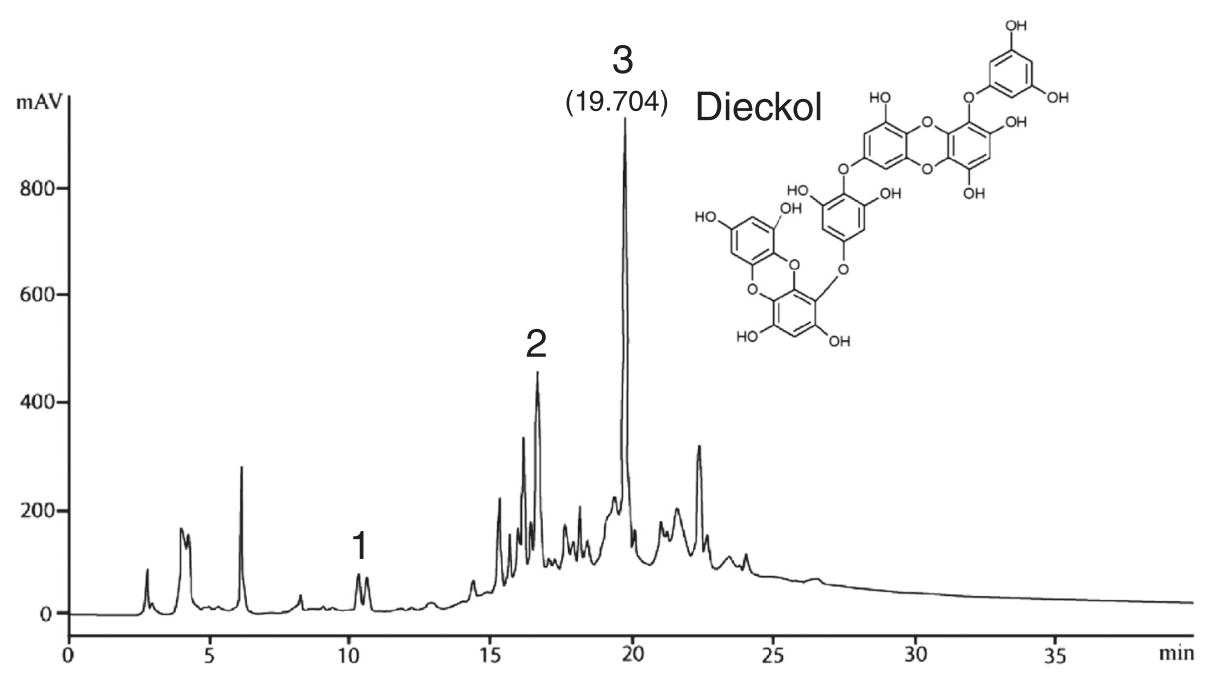

Fig. $2 \mathrm{HPLC}$ analysis of E. cava hydrolysate. Column: $4.6 \mathrm{~mm} \times 250 \mathrm{~mm}$. Separation was performed with a gradient from 5 to $60 \%$ acetonitrile in $30 \mathrm{~min}$ at a flow rate of $1.0 \mathrm{~mL} / \mathrm{min}$. Elution was monitored at $230 \mathrm{~nm}$ (injection volume, $20 \mu \mathrm{L}(1 \mathrm{mg} / \mathrm{mL})$ ). 1; phologlucinol, 2; eckol, 3; dieckol 
A

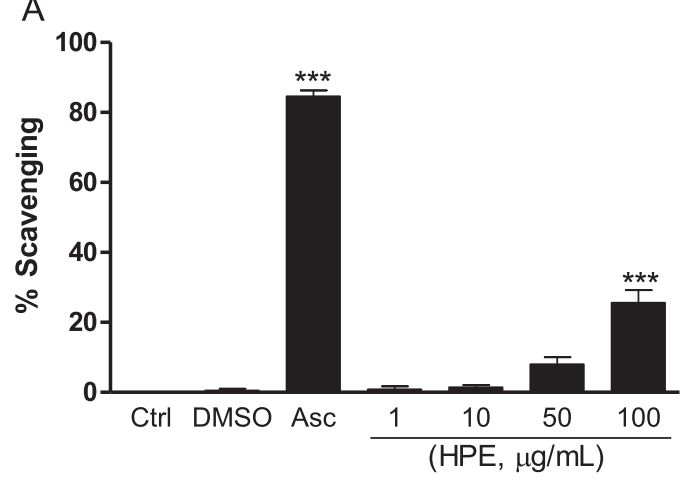

C

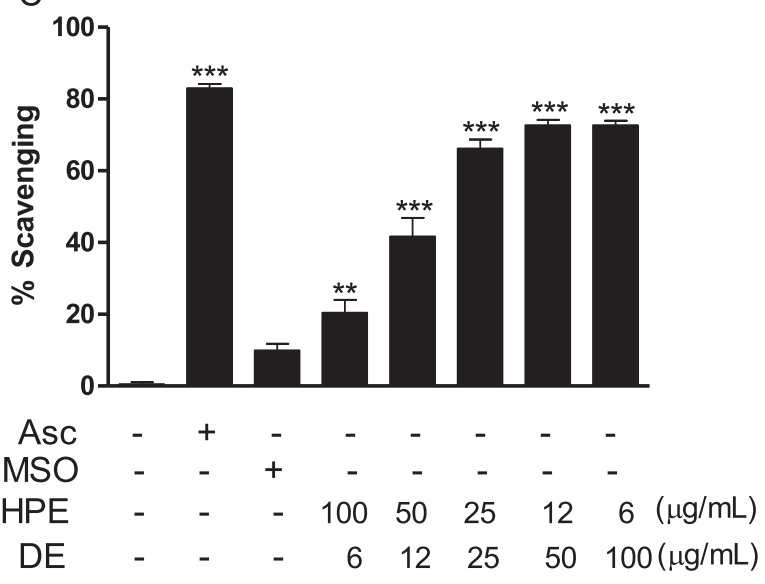

B

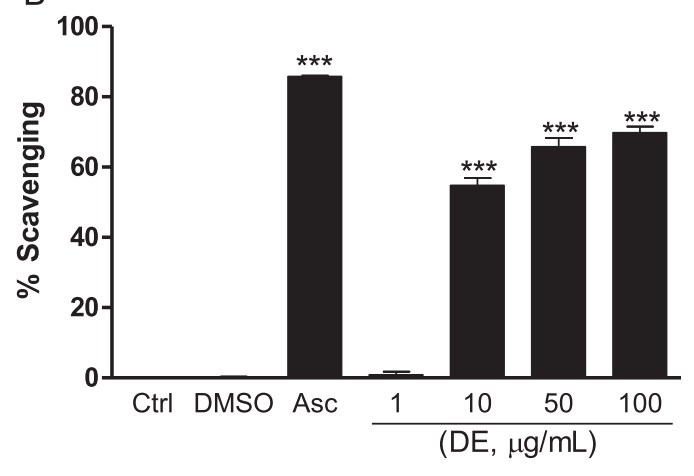

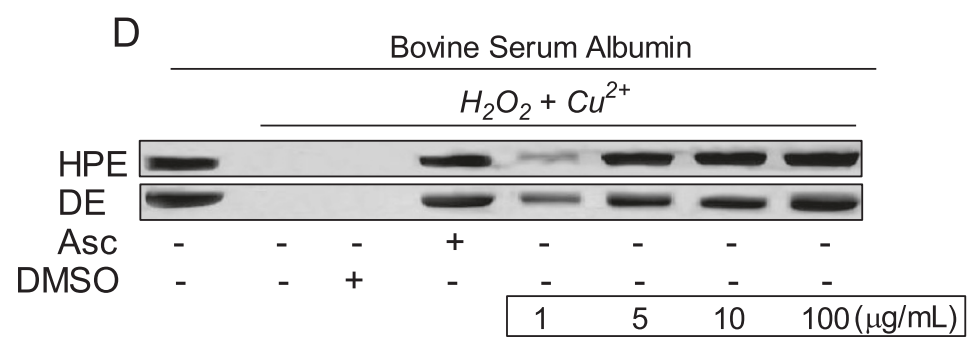

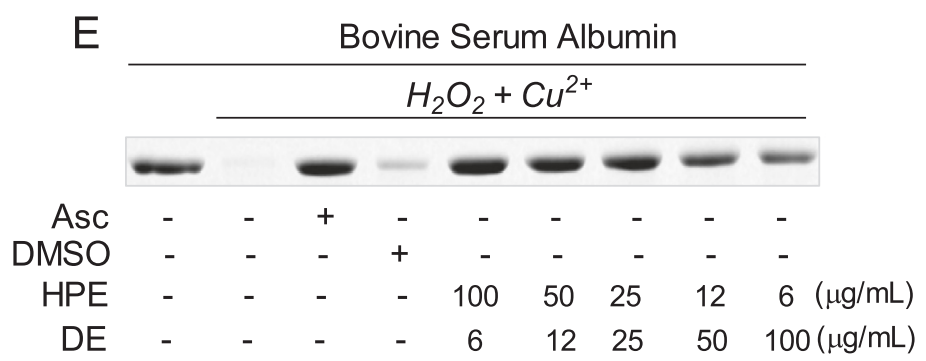

Fig. 3 (See legend on next page.) 
(See figure on previous page.)

Fig. 3 Radical scavenging activity. a-c DPPH free radical scavenging activity of the HPE, DE, and HPE:DE at different concentrations (1-100 $\mu$ g/mL) was determined for a fixed time $(20 \mathrm{~min})$. d-e Polyacrylamide gel electrophoresis (PAGE) profiles show the protein obtained without treatment, with $\mathrm{Cu}^{2+} / \mathrm{H}_{2} \mathrm{O}_{2}$, and at different concentrations of the HPE or DE. Ascorbic acid (Asc. $0.1 \mathrm{mM}$ ) and $10 \%$ DMSO were used as positive and vehicle controls, respectively. The final steps included incubating all of the reactants, including BSA, for $2 \mathrm{~h}$, followed by $10 \%$ sodium dodecyl sulfate-PAGE. Results are expressed as means \pm standard deviations from three separate experiments. ${ }^{*} P<0.05,{ }^{* * *} P<0.001$ vs. Ctrl. Ctrl, control

$\mathrm{H}_{2} \mathrm{O}_{2}$ in the presence and absence of the samples. The control antioxidant was $0.1 \mathrm{mM}$ ascorbate, which was directly dissolved in PBS. The reactions were carried out in open tubes and placed in a shaking water bath maintained at $37^{\circ} \mathrm{C}$. After the reaction was complete, each mixture was separated by $10 \%$ sodium dodecyl sulfate-polyacrylamide gel electrophoresis and stained with $0.1 \%$ Coomassie Blue Brilliant solution.

\section{Elastase inhibition assay}

This assay was performed in $0.2 \mathrm{mM}$ Tris- $\mathrm{HCl}$ buffer ( $\mathrm{pH}$ 8.0) in accordance with a previous study with minor modifications [22]. In brief, porcine pancreatic elastase (Sigma-Aldrich) was dissolved to prepare a $3.33 \mathrm{mg} / \mathrm{mL}$ stock solution in sterile water. The $\mathrm{N}$-succinyl-Ala-Ala-Ala$p$-nitroanilide substrate was dissolved in buffer to $1.6 \mathrm{mM}$. The test hydrolysates were incubated with the enzyme for $20 \mathrm{~min}$ before adding substrate to begin the reaction. The final reaction mixture ( $250 \mu \mathrm{L}$ total volume) contained buffer, $0.8 \mathrm{mM}$ substrate, $1 \mu \mathrm{g} / \mathrm{mL}$ enzyme, and various concentrations of HPE, DE, and HPE:DE, as indicated. Asc $(100 \mu \mathrm{M})$ was used as the positive control. Absorbance values between 381 and $402 \mathrm{~nm}$ were measured immediately following addition of the substrate and then continuously for 20 min using a Spectra Max 340 Microplate Reader in Nunc 96 well microtiter plates. The percent inhibition of elastase was calculated as follows: Inhibition $(\%)=[($ ODcontrol - ODsample $) /$ ODcontrol $] \times 100$.

\section{Cell culture}

Human fibroblast (CCD986sk), mouse myoblast (C2C12), and neuroblastoma cell lines $(\mathrm{N} 2 \mathrm{a})$ (Korean Cell Line Bank, Seoul, Republic of Korea) were grown in Dulbecco's Modified Eagle's Medium (DMEM) (Hyclone. Logan, UT, USA.) supplemented with $10 \%$ fetal bovine serum, $100 \mathrm{U} /$ $\mathrm{mL}$ penicillin, and $100 \mu \mathrm{g} / \mathrm{mL}$ streptomycin (Invitrogen, Carlsbad, CA, USA.). The cultures were maintained under $5 \% \mathrm{CO}_{2}$ at $37{ }^{\circ} \mathrm{C}$ in tissue culture flasks. The cells were grown to $>90 \%$ confluency and subjected to no more than 20 cell passages. Media were changed every 2-3 days. Subconfluent cells were harvested and seeded at a density of $5 \times 10^{5}$ cells or $1.5 \times 10^{6}$ cells into poly-L-lysine-coated $35-\mathrm{mm}$ or $60-\mathrm{mm}$ culture plates. After plating for $24 \mathrm{~h}$, the medium was replaced with serum-free DMEM, washed once with phosphate-buffered saline (PBS), and treated with $\mathrm{HPE}, \mathrm{DE}$, or the positive controls of phorbol myristic acetate (PMA), and ascorbic acid (Asc) (Sigma-Aldrich, St. Louis, MO, USA.).

\section{Cell viability}

Cell viability in response to HPE and DE stimulation was investigated in 96-well microtiter plates $\left(2 \times 10^{4}\right.$ cells $/ \mathrm{mL}$ ) following a 24-h culture using the Cell Counting Kit-8 (CCK-8; Dojindo Laboratories, Kumamoto, Japan). This system uses WST-8 [2-(2-methoxy-4-nitrophenyl)3-(4-nitrophenyl)-5-(2,4-disulfophenyl)-2H-tetrazolium, monosodium salt], which produces water-soluble colored formazan upon bioreduction in the presence of the electron carrier, 1-methoxy-5-methylphenazinium methylsulfate. The plates were measured at $450 \mathrm{~nm}$ (Spectra Max 340, Molecular Devices, Sunnyvale, CA, USA.), and data from triplicate cultures are expressed as percent viability vs. the control.

\section{Quantitative real-time polymerase chain reaction (PCR) assay}

Total RNA hydrolysates from each cell line were prepared using the Trizol method (Invitrogen). cDNA was synthesized from RNA by reverse transcription of $1 \mu \mathrm{g}$ of total RNA using the Improm-II reverse transcription system (Promega, Madison, WI, USA.) and oligo dT primers in a total volume of $20 \mu \mathrm{L}$. PCR amplification was performed using the primers described in Table 1 (Bioneer, Deajeon, Republic of Korea). Quantitative realtime PCR reactions were run on a Rotor-Gene 6000 (Corbett Research, Sydney, Australia) using SYBR Green PCR Master Mix (Qiagen, Valencia, CA, USA.) in 20- $\mu \mathrm{L}$ reaction mixtures. Each real-time-PCR master mix contained $10 \mu \mathrm{L} 2 \times$ enzyme Mastermix, 7.0 $\mu \mathrm{L}$ RNase free water, $1 \mu \mathrm{L}$ of each primer (10 pM each), and $1 \mu \mathrm{L}$ diluted template. The PCR was performed with an initial pre-incubation step for $10 \mathrm{~min}$ at $95{ }^{\circ} \mathrm{C}$, followed by 45 cycles of $95{ }^{\circ} \mathrm{C}$ for $15 \mathrm{~s}$, annealing at $52{ }^{\circ} \mathrm{C}$ for $15 \mathrm{~s}$, and extension at $72{ }^{\circ} \mathrm{C}$ for $10 \mathrm{~s}$. A melting curve analysis was used to confirm formation of the expected PCR product, and products from all assays were tested additionally by $1.2 \%$ agarose gel electrophoresis to confirm the correct lengths. An inter-run calibrator was used, and a standard curve was created for each gene to obtain PCR efficiencies. Relative sample expression levels were calculated using Rotor-Gene 6000 Series Software 1.7 and were expressed relative to glyceraldehyde 3-phosphate dehydrogenase and corrected for between-run variability. 

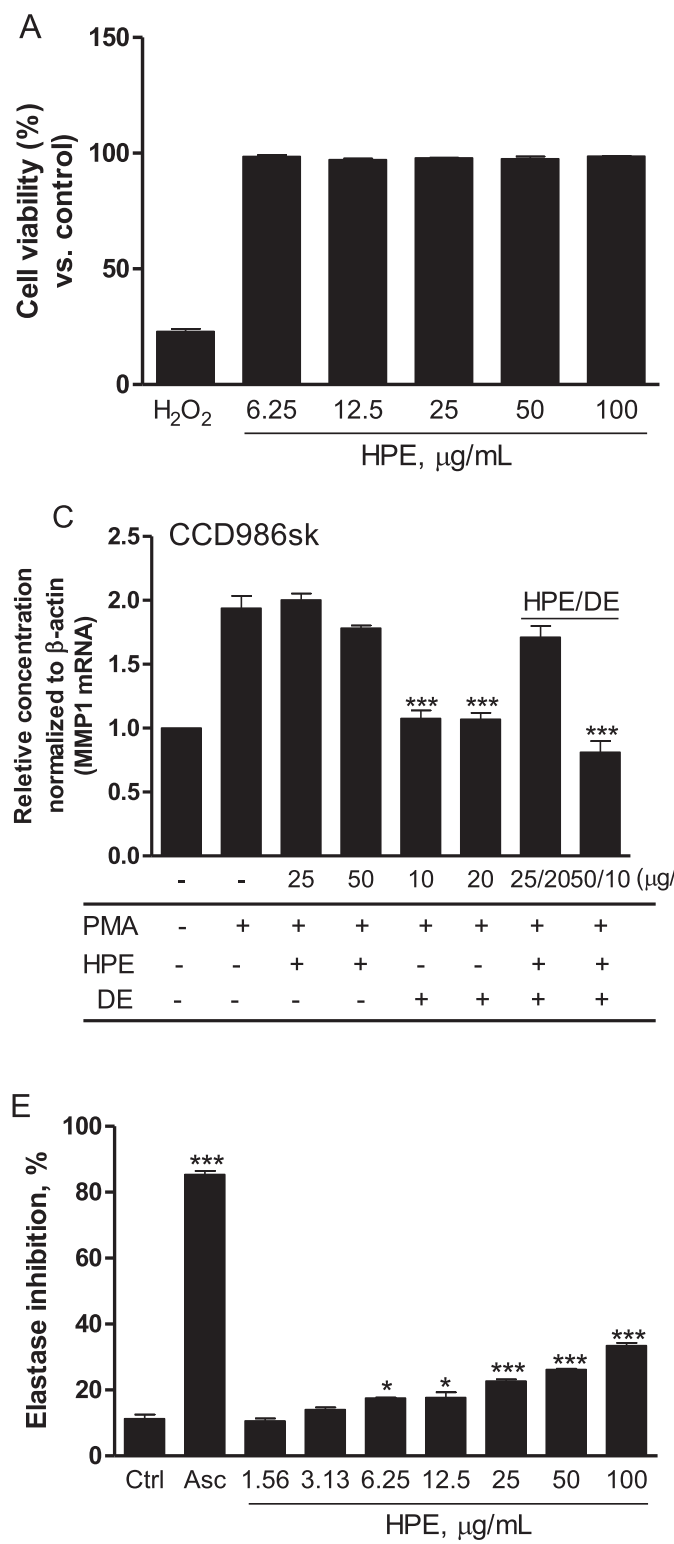

G
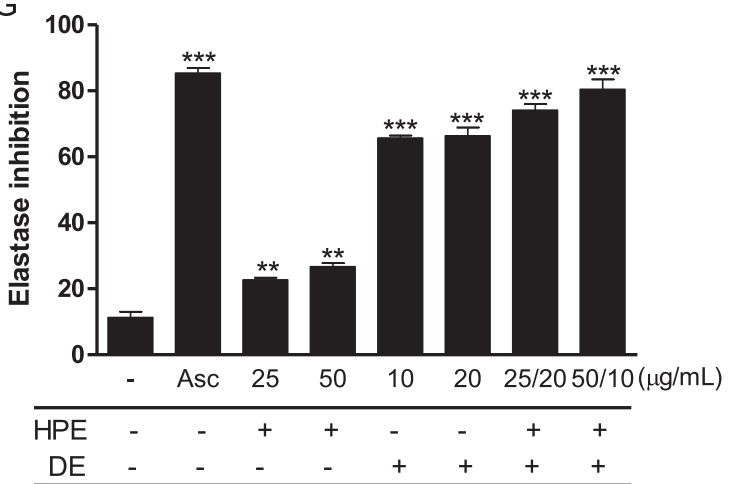

Fig. 4 (See legend on next page.)
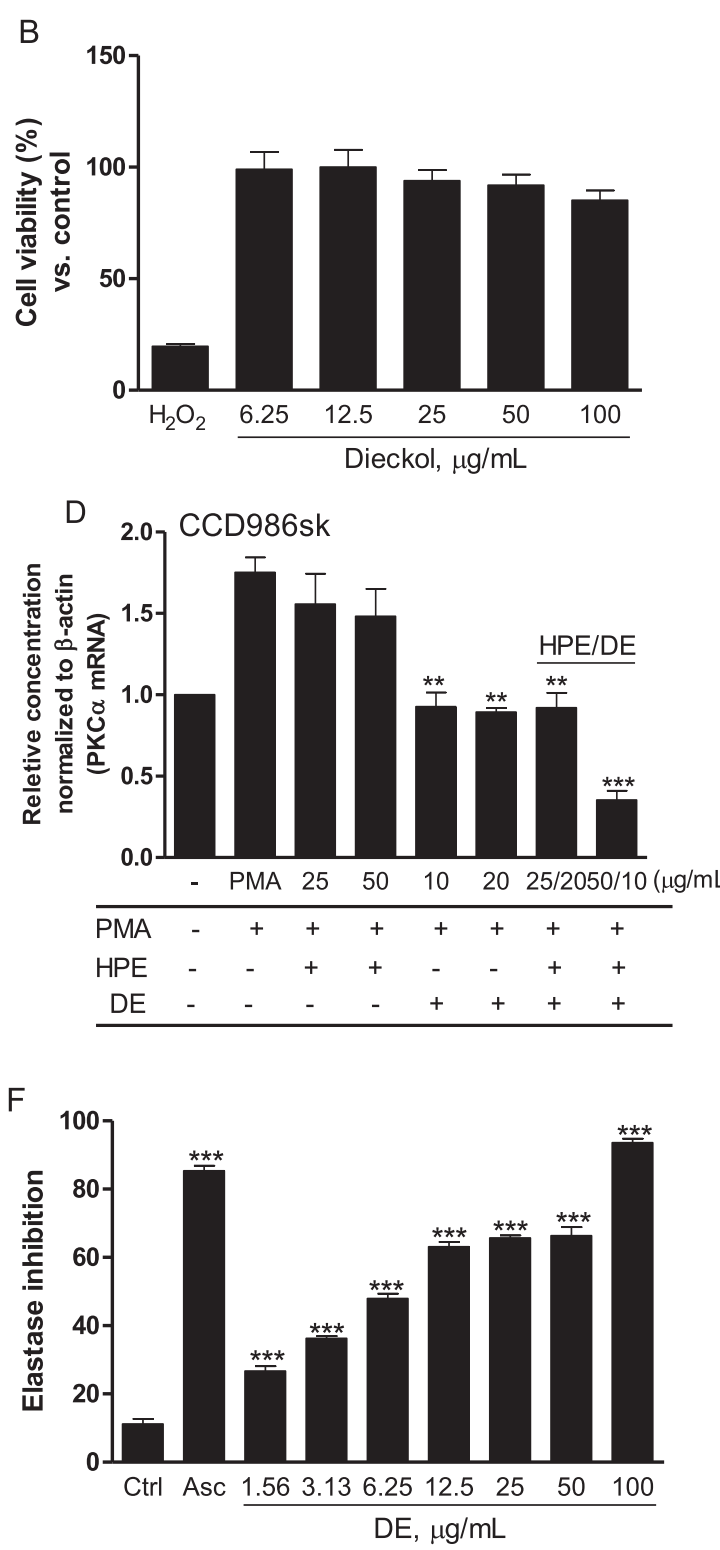
(See figure on previous page.)

Fig. 4 Effect on matrix metalloproteinase-1/protein kinase-a (MMP1/PCKa) gene expression in CCD986sk and elastinase activity. a, b Cell viability assays were performed, and the results were expressed as the percent viability for identical treatments of HPE and DE (6.25-100 $\mu \mathrm{g} / \mathrm{mL})$. Cells were seeded on 12-well culture plates and treated with the HPE and DE in the presence or absence of 50 HM phorbol myristic acetate (PMA) for 24 h. c, d MMP1 and PKCa mRNAs were quantified by fold units using the real-time polymerase chain reaction. e-g Elastase activity was measured between 381 and $402 \mathrm{~nm}$ immediately after adding the substrate. Results are expressed as means \pm standard deviations from three separate experiments. ${ }^{*} P<0.05$, ${ }^{* *} P$ $<0.01,{ }^{* *} P<0.001$ vs. PMA (c and $\left.\mathbf{d}\right)$ or vs. Ctrl (e, f, and $\mathbf{g}$ )

Data are expressed as a percentage of the internal control gene.

Immunocytochemistry (ICC) and microscopic observations Cultured N2a cells were fixed in $4 \%$ paraformaldehyde in PBS for 15 min, washed twice with PBS supplemented with $100 \mathrm{mM}$ glycine for $5 \mathrm{~min}$, and incubated with permeabilization buffer consisting of $0.1 \%$ Triton X-100 (Sigma-Aldrich) in PBS for $30 \mathrm{~min}$ at room temperature. Blocking was performed with $1 \%$ BSA for $30 \mathrm{~min}$ at room temperature as previously described [23]. Then, choline acetyltransferase (ChAT) or vesicular acetylcholine transporter (VAChT) mouse monoclonal antibody (1:200; Santa Cruz Biotechnology, Santa Cruz, CA, USA.) was added to $1 \%$ BSA in PBS with Tween 20 and incubated for $2 \mathrm{~h}$ at room temperature. The cells were washed three times with PBS before fluorescein isothiocyanate-conjugated antimouse immunoglobulin G (1:200; Cell Signaling Technology, Danvers, MA, USA.) was added to $1 \%$ BSA for $1 \mathrm{~h}$ at room temperature. The cells were rinsed and counterstained with 4,6-diamidino-2-phenylindole (Sigma-Aldrich) for $10 \mathrm{~min}$, followed by two PBS washes. The cultures were visualized with an inverted fluorescent microscope system (Eclipse Ti-S; Nikon, Tokyo, Japan) at a magnification of $\times 600$.

\section{Statistical analysis}

Statistical comparisons between groups were performed using one-way analysis of variance with Dunnet's post-hoc test and SPSS v. 17 software (SPSS, Inc., Chicago, IL, USA.). A $p<0.05$ was considered significant.

\section{Results and discussion}

Among many the age-related changes that begins in adulthood, muscle weakness, cognitive decline, and the accumulation of reactive oxygen species (ROS) are closely related because ROS are major causative factors of aging through their oxidative deteriorating effects $[24,25]$. Neurodegenerative diseases and the degenerative loss of skeletal muscle mass (sarcopenia) during aging are critically linked to mitochondrial dysfunction, which cannot functionally regulate or scavenge ROS via antioxidant enzymes, such as superoxide dismutase (SOD), catalase, and glutathione peroxidase [26, 27]. In addition, the main amino acid reservoir in the body is skeletal muscle, which contains approximately $75 \%$ of all protein and progressively loses muscle mass and function during aging [28].

In this respect, our results show that the HPE contained 17 amino acids, including nine essential amino acids and eight nonessential amino acids. Among the total amino acids, the quantity of sulfur-containing amino acids (cysteine and methionine) and aromatic amino acids (phenylalanine and tyrosine) was 0.62 and $1.82 \mathrm{~g} / 100 \mathrm{~g}$, respectively. As cysteine has potent antioxidant capacity, it is believed that the HPE may contribute to improve various age-related degenerative processes caused by ROS [29, 30]. Furthermore, the balanced essential and nonessential amino acids in the HPE may prevent the decline in baseline muscle protein synthesis, which promotes sarcopenia [31]. The amino acid profile of the HPE is shown in Table 2. Among the 17 amino acids, the major amino acids were glutamine (4.13 g/100 g), followed by glycine, asparagine, leucine, proline, lysine, arginine, alanine, and valine, which constituted $>76.3 \%$ of the total amino acids contained in the HPE proteins (Table 2). The amount of nonessential amino acids was higher (52.9\%) than that of the essential amino acids (47.1\%). Figure 1 shows the amino acid chromatograms in the HPE.

In addition, we determined phlorotannins in a $70 \%$ ethanol extract from E. cava using high performance liquid chromatography (HPLC) analysis (Fig. 2). Phlorotannins

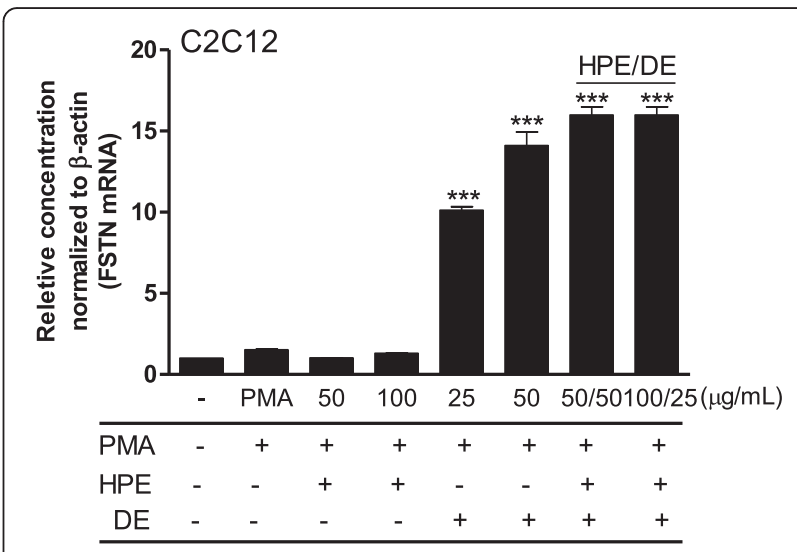

Fig. 5 Effect on follistatin (FSTN) gene expression in C2C12. Cells were seeded on 12-well culture plates and treated with the HPE and DE in the presence or absence of $50 \mu \mathrm{M}$ phorbol myristic acetate (PMA) for $24 \mathrm{~h}$. FSTN mRNA was quantified by fold units using the real-time polymerase chain reaction. Results are expressed as means \pm standard deviations from three separate experiments. ${ }^{* *} P<0.001$ vs. PMA 
(phloroglucinol, eckol, and dieckol) was confirmed by comparing their liquid chromatography-mass spectrometry (LC-MS), proton Nuclear Magnetic Resonance $\left({ }^{1} \mathrm{H}\right.$ NMR) data to the previous report [13].

In the DPPH assay, HPE scavenged free radicals beginning at a concentration of $50 \mu \mathrm{g} / \mathrm{mL}$, whereas DE showed higher activity at a lower concentration $(10 \mu \mathrm{g} / \mathrm{mL})$ (Fig. 3a, b). More enhanced scavenging effects were found when the two agents were combined (Fig. 3c). Notably, the combination of HPE $(25 \mu \mathrm{g} / \mathrm{mL})$ and DE $(25 \mu \mathrm{g} / \mathrm{mL})$ was the most beneficial concentration. This result was confirmed in the hydroxyl radical-mediated oxidation assay, which determined the protection of protein degradation. Degradation of BSA by hydroxyl radicals produced from $\mathrm{Cu}^{2+}$ and $\mathrm{H}_{2} \mathrm{O}_{2}$ was monitored in the presence of single HPE/DE or HPE:DE combination. As shown in

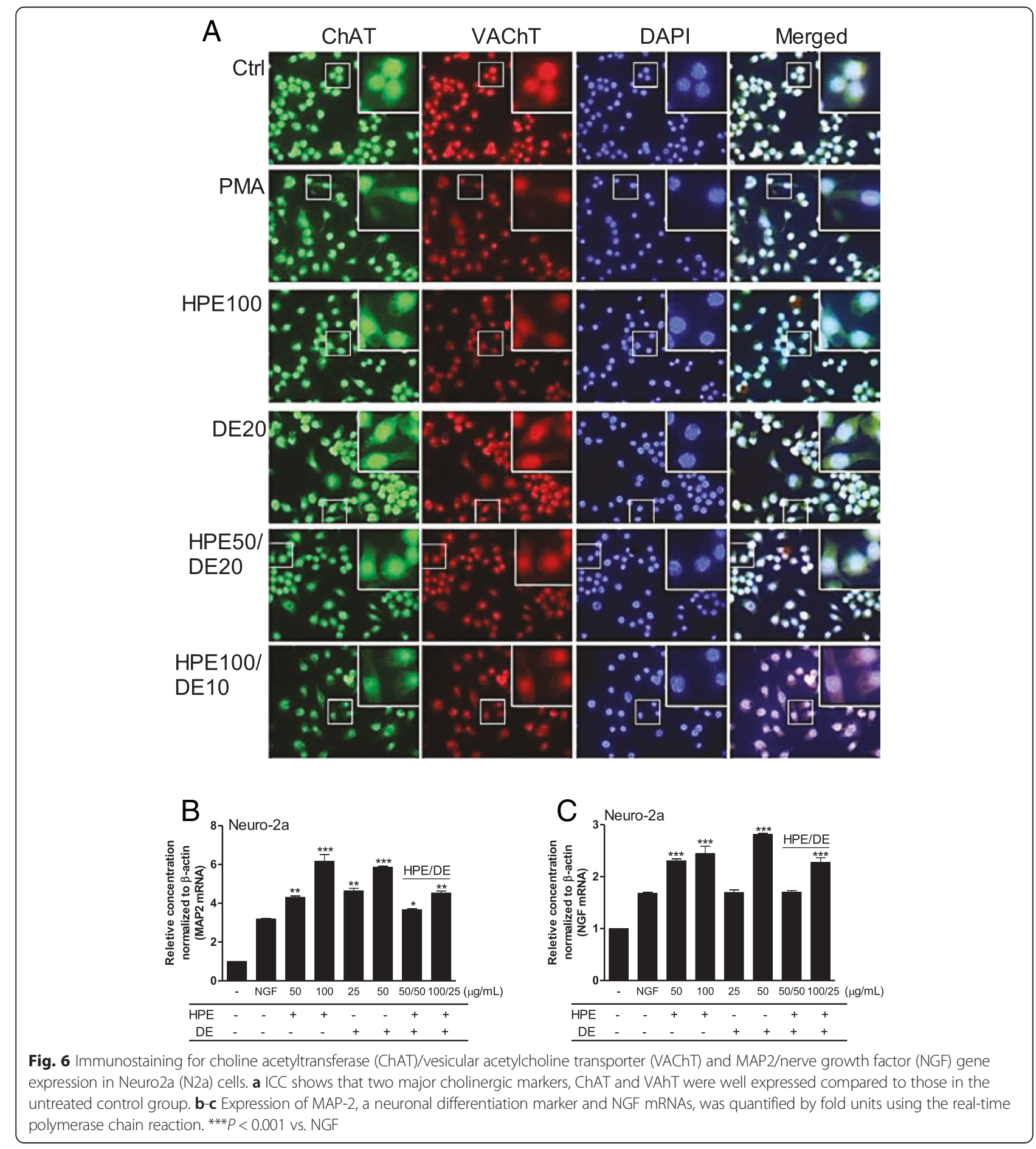


Fig. 3d-e, hydroxyl radical scavenging activity was dosedependently detected in both single treatments, whereas $25 \mu \mathrm{g} / \mathrm{mL}$ HPE:DE combination displayed high antioxidant activity. It is uncertain why higher DE and lower HPE combination displayed weak activity in protecting protein from hydroxyl radical attack. However, one possibility is that amino acids can act as a chelating agent for copper ions, thus alleviating generation of hydroxyl radical, while the multifunctional antioxidant activity of polyphenols is largely related to phenol rings which act as electron traps [32]. These scavenging effects indicate that the HPE:DE combination would provide more therapeutic advantages as an anti-aging therapy than those of a single component treatment.

MMP1 and PKCa mRNAs, which increase agedependently, were examined in the CCD986sk human fibroblast cell line, which was not cytotoxic when incubated with HPE or DE at about $100 \mu \mathrm{g} / \mathrm{mL}$. As collagen and elastin fiber atrophy in skin is predominant during aging due to increased expression of their degradative enzymes, the decrease of MMP1/PKC $\alpha$ mRNA expression would be the first choice for an anti-aging therapy. The results revealed that DE successfully inhibited MMP1 and PKC $\alpha$ mRNA expression, whereas HPE did not. However, both genes were remarkably inhibited at a higher concentration when the two were combined (50:10 $\mu \mathrm{g} / \mathrm{mL}$ HPE:DE) (Fig. 4a and b), suggesting that HPE:DE results in efficient formation of collagen [33, 34]. Consistently, elastase activity was well inhibited after the DE and HPE treatments. Interestingly, optimal inhibition of elastase occurred after the combined HPE:DE treatment (Fig. 4c-e). These data strongly indicate that degradation of collagen and elastin fibers was diminished following the HPE:DE treatment. This indicates that HPE would synergistically play a role in skin revitalization and rejuvenation by improving skin elasticity and thickness along with enhancing skin texture [8].

Because muscle weakness and loss of muscle mass in the form of sarcopenia are major changes during aging, the increased protein synthesis and decreased protein degradation in hypertrophied muscle are important events in aging. Therefore, the overexpression of FSTN, which is essential for muscle fiber formation and growth, may be the major event regulating musculoskeletal aging [35]. Our data showed that HPE alone did not increase FSTN expression in $\mathrm{C} 2 \mathrm{C} 12$ myoblast cells, whereas $\mathrm{DE}$ significantly increased FSTN expression, suggesting improved muscle fiber formation and growth. However, FSTN expression was much more enhanced following cotreatment with HPE:DE (Fig. 5). As the older muscle is still able to respond to amino acids, which have been shown to acutely stimulate muscle protein synthesis in older individuals, plenty amounts of leucine and glutamine in HPE are synergistically to stimulate muscle protein synthesis and to maintain muscle tissue by preserving lean tissue mass [36, 37].

On the other hand, we previously reported that ChAT overexpressing human neural stem cells restore cognition by increasing of acetylcholine levels in a rat model [38]. Thus, we evaluated whether HPE and DE increase ChAT and VAChT expression, which are required for cholinergic neurotransmission and coordinately contribute significantly to increase intracellular acetylcholine in cholinergic neurons [39]. ChAT and VAChT mRNA were distinctively expressed in N2a neuroblastoma cells, after the HPE and DE treatments (Fig. 6a), suggesting a functional contribution by HPE and DE in neuronal differentiation and cholinergic gene expression. Notably, MAP-2, a neuronal differentiation marker, and NGF mRNAs increased significantly either with HPE or DE alone or in combination, dose-dependently (Fig. 6b and c). Our data clearly showed that the HPE and DE effectively enhanced ChAT and VAChT expression and the significant increase in MAP-2 and NGF mRNA expression in N2a cells. These evidences clearly supported that either HPE:DE combination or single treatment can promote the differentiation and stable growth of neuronal cells, indicating an effective decrease against aging-induced cognitive impairments [40].

\section{Conclusions}

The HPE:DE combination effectively improved free radical scavenging, muscle hypertrophy-related FSTN mRNA expression, ameliorated cognition-related genes (ChAT and VAChT) and proteins, and inhibited MMP1/PKC $\alpha$ expression and elastinase activity, suggesting that the combined treatment of HPE:DE may be useful for anti-aging therapy in which the accumulation of oxidative damage is the main driving force.

\section{Competing interests}

The authors declare that they have no competing interests.

\section{Authors' contributions}

SSJ idealized and designated the study. SKJ and DIL performed and coordinated the experiments. STK, KHK and DWP helped with the cell culture and biochemical analysis and data mining. JKC, YBL, NSH and YBK improved the style of manuscript by editing English. $\mathrm{DH}$ and $\mathrm{JH}$ helped with the preparation of human placental hydrolysate and dieckol. All authors read and approved the final manuscript.

Authors' information

Not Applicable.

\section{Acknowledgement}

This research was supported by High Value-added Food Technology Development Program, Ministry of Agriculture, Food and Rural Affairs (MAFRA; grant number 113034-3).

\section{Author details}

'Department of Marine Molecular Biotechnology, College of Life Science, Gangneung-Wonju National University, 120 Gangneung Daehangno, Gangneung, Gangwon 210-702, Republic of Korea. ${ }^{2}$ College of Pharmacy, Chung-Ang University, Heuksuk-dong, Dongjak-gu, Seoul 156-756, Republic 
of Korea. ${ }^{3}$ Industry-Academic Cooperation Foundation, Hanbat National University, Daejeon 305-719, Republic of Korea. ${ }^{4}$ Central Research Institute, Dr. Chung's Food Co. Ltd., Chungbuk 361-782, Republic of Korea. ${ }^{5}$ Chungbuk National University, Chungbuk 361-763, Republic of Korea. ${ }^{6}$ DF-Dr. Han Biotech., Shaoyaojubeili, Chaoyang District, Beijing 10029, China.

Received: 7 July 2015 Accepted: 23 September 2015

Published online: 05 October 2015

\section{References}

1. López-Otín C, Blasco MA, Partridge L, Serrano M, Kroemer G. The hallmarks of aging. Cell. 2013;153:1194-217.

2. Bowles D, Torgan C, Ebner S, Kehrer JP, Ivy JL, Starnes JW. Effects of acute, submaximal exercise on skeletal muscle vitamin E. Free Radic Res Commun. 1991;14:139-43.

3. Meydani M, Evans WJ, Handelman G, Biddle L, Fielding RA, Meydani SN, et al. Protective effect of vitamin $\mathrm{E}$ on exercise-induced oxidative damage in young and older adults. Am J Physiol. 1993;264:992-8.

4. Fusco D, Colloca G, Lo Monaco MR, Cesari M. Effects of antioxidant supplementation on the aging process. Clin Interv Aging. 2007;2:377-87.

5. Berr C, Richard MJ, Gourlet V, Garrel C, Favier A. Enzymatic antioxidant balance and cognitive decline in aging-the EVA study. Eur J Epidemiol. 2004;19:133-8.

6. Villeda SA, Luo J, Mosher Kl, Zou B, Britschgi M, Bieri G, et al. The ageing systemic milieu negatively regulates neurogenesis and cognitive function. Nature. 2011:477:90-4.

7. Carotti D, Allegra E. An approach to chemical characterization of human placental extracts: proteins, peptides, and amino acids analyses. Physiol Chem Phys. 1981;13:129-36.

8. Kong M, Park SB. Effect of human placental extract on health status in elderly Koreans. Evid Based Complement Alternat Med. 2012;2012:732915.

9. Datta P, Bhattacharyya D. Spectroscopic and chromatographic evidences of NADPH in human placental extract used as wound healer. J Pharma Biomed Anal. 2004;34:1091-8.

10. Jash A, Kwon HK, Sahoo A, Lee CG, So JS, Kim J, et al. Topical application of porcine placenta extract inhibits the progression of experimental contact hypersensitivity. J Ethnopharmacol. 2011;133:654-62.

11. Biswas TK, Auddy B, Bhattacharyya NP, Bhattacharyya S, Mukherjee B. Wound healing activity of human placental extract in rats. Acta Pharmacol Sin. 2001;22:1113-6.

12. Kang HS, Chung HY, Kim JY, Son BW, Jung HA, Choi JS. Inhibitory phlorotannins from the edible brown alga Ecklonia stolonifera on total reactive oxygen species (ROS) generation. Arch Pharm Res. 2004;27:194-8.

13. Li Y, Qian ZJ, Ryu B, Lee SH, Kim MM, Kim SK. Chemical components and its antioxidant properties in vitro: an edible marine brown alga. Ecklonia cava Bioorg Med Chem. 2009;17:1963-73.

14. Fukuyama $Y$, Kodama M, Miura I, Kinzyo Z, Mori H, Nakayama Y, et al. Anti-plasmin inhibitor. VI. Structure of phlorofucofuroeckol A, a novel phlorotannin with both dibenzo-1,4-dioxin and dibenzofuran elements, from Ecklonia kurome Okamura. Chem Pharm Bull. 1990;38:133-5.

15. Ahn MJ, Yoon KD, Min SY, Lee JS, Kim JH, Kim TG, et al. Inhibition of HIV-1 reverse transcriptase and protease by phlorotannins from the brown alga Ecklonia cava. Biol Pharm Bull. 2004;27:544-7.

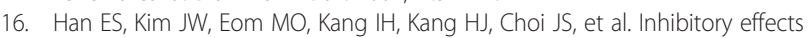
of Ecklonia stolonifera on gene mutation on mouse lymphoma tk+/- locus in L5178Y-3.7.2C cell and bone marrow micronuclei formation in ddY mice. Environ Mutagen Carcinogen. 2000;20:104-11.

17. Kang SM, Heo SJ, Kim KN, Lee SH, Yang HM, Kim AD, et al. Molecular docking studies of a phlorotannin, dieckol isolated from Ecklonia cava with tyrosinase inhibitory activity. Bioorg Med Chem. 2012;20:311-6.

18. Jung HA, Jung HJ, Jeong HY, Kwon HJ, Ali MY, Choi JS. Phlorotannins isolated from the edible brown alga Ecklonia stolonifera exert anti-adipogenic activity on 3 T3-L1 adipocytes by downregulating C/EBPa and PPARY. Fitoterapia. 2014;92:260-9.

19. Joe MJ, Kim SN, Choi HY, Shin WS, Park GM, Kang DW, et al. The inhibitory effects of eckol and dieckol from Ecklonia stolonifera on the expression of matrix metalloproteinase-1 in human dermal fibroblasts. Biol Pharm Bull. 2006:29:1735-9.

20. Kang MC, Kim KN, Kang SM, Yang X, Kim EA, Song CB, et al. Protective effect of dieckol isolated from Ecklonia cava against ethanol caused damage in vitro and in zebrafish model. Environ Toxicol Pharmacol. 2013;36:1217-26.
21. Mayo JC, Tan DX, Sainz RM, Natarajan M, Lopez-Burillo S, Reiter RJ. Protection against oxidative protein damage induced by metal-catalyzed reaction or alkylperoxyl radicals: comparative effects of melatonin and other antioxidants. Biochim Biophys Acta. 2003;1620:139-50.

22. Kim YJ, Uyama H, Kobayashi S. Inhibition effects of (+)-catechin-aldehyde polycondensates on proteinases causing proteolytic degradation of extracellular matrix. Biochem Biophys Res Commun. 2004;320:256-61.

23. Jang SK, Yu JM, Kim ST, Kim GH, Park da W, Lee do I, et al. An Aß42 uptake and degradation via $\mathrm{Rg} 3$ requires an activation of caveolin, clathrin and Aß-degrading enzymes in microglia. Eur J Pharmacol. 2015;758:1-10.

24. Afanas'ev IB. Free radical mechanisms of aging processes under physiological conditions. Biogerontology. 2005;6:283-90.

25. Harman D. Aging: a theory based on free radical and radiation chemistry. J Gerontol. 1956;11:298-300.

26. Alexeyev MF. Is there more to aging than mitochondrial DNA and reactive oxygen species? FEBS J. 2009;276:5768-87.

27. Lagouge M, Larsson NG. The role of mitochondrial DNA mutations and free radicals in disease and ageing. J Intern Med. 2013;273:529-43.

28. Fujita S, Volpi E. Amino acids and muscle loss with aging. J Nutr. 2006;136:277-80.

29. Dröge $\mathbf{W}$. Oxidative stress and ageing: is ageing a cysteine deficiency syndrome? Philos Trans R Soc Lond B Biol Sci. 2005;360:2355-72.

30. Meucci E, Mele M. Amino acids and plasma antioxidant capacity. Amino Acids. 1997;12:373-7

31. Houston DK, Nicklas BJ, Ding J, Harris TB, Tylavsky FA, Newman AB, et al. Dietary protein intake is associated with lean mass change in older, community-dwelling adults: the Health, Aging, and Body Composition (Health ABC) Study. Am J Clin Nutr. 2008;87:150-5.

32. Fukumoto LR, Mazza G. Assessing antioxidant and prooxidant activities of phenolic compounds. J Agric Food Chem. 2000;48:3597-604.

33. Sudbeck BD, Parks WC, Welgus HG, Pentland AP. Collagen-stimulated induction of keratinocyte collagenase is mediated via tyrosine kinase and protein kinase C activities. J Biol Chem. 1994;269:30022-9.

34. Ricciarelli R, Maroni P, Ozer N, Zingg JM, Azzi A. Age-dependent increase of collagenase expression can be reduced by alpha-tocopherol via protein kinase C inhibition. Free Radic Biol Med. 1999;27:729-37.

35. Bowser $M$, Herberg $S$, Arounleut $P$, Shi $X$, Fulzele $S$, Hill WD, et al. Effects of the activin A-myostatin-follistatin system on aging bone and muscle progenitor cells. Exp Gerontol. 2013;48:290-7.

36. Dardevet D, Sornet C, Balage M, Grizard J. Stimulation of in vitro rat muscle protein synthesis by leucine decreases with age. J Nutr. 2000;130:2630-5.

37. Lacey JM, Wilmore DW. Is glutamine a conditionally essential amino acid? Nutr Rev. 1990;48:297-309.

38. Park D, Joo SS, Kim TK, Lee SH, Kang H, Lee HJ, et al. Human neural stem cells overexpressing choline acetyltransferase restore cognitive function of kainic acid-induced learning and memory deficit animals. Cell Transplant. 2012;21:365-71.

39. Berse B, Blusztain JK. Coordinated up-regulation of choline acetyltransferase and vesicular acetylcholine transporter gene expression by the retinoic acid receptor alpha, CAMP, and leukemia inhibitory factor/ciliary neurotrophic factor signaling pathways in a murine septal cell line. J Biol Chem. 1995;270:22101-4.

40. Levin ED, Christopher NC, Crapo JD. Memory decline of aging reduced by extracellular superoxide dismutase overexpression. Behav Genet. 2005;35:447-53.

\section{Submit your next manuscript to BioMed Central and take full advantage of:}

- Convenient online submission

- Thorough peer review

- No space constraints or color figure charges

- Immediate publication on acceptance

- Inclusion in PubMed, CAS, Scopus and Google Scholar

- Research which is freely available for redistribution 